\title{
A Study on the Flipped Classroom Model for College English Education
}

\author{
QU Li-li \\ University of Shanghai for Science and Technology, Shanghai, China
}

\begin{abstract}
The flipped classroom, as an innovative instructional approach, has currently drawn much attention from the educational field and caused the rise of teaching reforms worldwide. Integrated with technology-enhanced learning resources, such as MOOCs, the flipped classroom is expected to bring positive changes to education. This paper mainly discusses the flipped classroom model for college English education from the perspective of educational objectives and implications are provided for research and practice of the flipped classroom.

Keywords: flipped classroom, college English, MOOCs
\end{abstract}

\section{Introduction}

The development of information technology will create more opportunities for education to realize some of its important goals in the 21 st century. Most prominently, the Internet has made education available and affordable to increasing numbers of people in the world. In the Information Age, new forms of education that incorporate technology are emerging, such as MOOCs (Massive Open Online Courses) and the flipped classroom, which have attracted considerable attention due to their promises in achieving important educational objectives. The flipped classroom concept has been adopted in different levels of education and various disciplines. However, it is not yet widely applied to foreign language teaching, especially at the tertiary level. This paper attempts to propose the flipped classroom model for college English education by drawing upon Bloom's taxonomy of educational objectives and discusses the role expectations of teachers and students in the flipped classroom.

\section{The Flipped Classroom in the Information Age}

In 2000, Lage, Platt, and Treglia first proposed the concept of "inverting the classroom" in their article "Inverting the Classroom: A Gateway to Creating an Inclusive Learning Environment". By "inverting the classroom", they mean "events that have traditionally taken place inside the classroom now take place outside the classroom and vice versa" (Lage, Platt, \& Treglia, 2000, p. 32). In 2011, Woodland Park High School teachers Jonathon Bergmann and Aaron Sams used the flipped classroom teaching approach: Students watched teacher-created videos in advance of class and class time was spent on problem solving and collaborative learning. The teachers commented that they had more time to work with individual students with the flipped classroom. Bergmann and Sams posted online lessons that were used by students and teachers across the U.S., wrote a book

QU Li-li, lecturer, Ph.D., College of Foreign Languages, University of Shanghai for Science and Technology, Shanghai, China. 
on the flipped classroom, and held "Flipped Class Conference" for teachers (Tucker, 2012). Bergmann and Sams's effective teaching model has inspired teachers around the world to practice the flipped classroom.

In the Information Age, the rise of MOOCs has created more opportunities for traditional classrooms to become flipped classrooms. MOOC platforms, such as Coursera, Udacity, and edX, offer free online courses from prestigious universities in the U.S. and around the world. Students from all over the world are now taking advantage of the online courses, which have obvious merits: low cost, easy access, and high flexibility.

However, according to YUAN and Powell (2013), MOOCs are mostly self-directed learning, distinct from formal instruction. The dropout rates in some MOOCs from Stanford, MIT (Massachusetts Institute of Technology), and UC Berkley (University of California-Berkeley) were as high as $80 \%-95 \%$. Moreover, MOOCs have been criticized for lack of pedagogy or inadequate pedagogy, thus unable to ensure quality. Some MOOCs can be compared to an online version of traditional teacher-centered instruction. The instructional model is dominated by lecture videos and quizzes, aiming to transmit knowledge. Other MOOCs, though providing collaborative learning experience, depend much on peer assessment for grading, because it is impossible for one teacher to grade thousands of assignments. Thus, the credibility of learning evaluation may be undermined.

MOOCs have attracted individual learners and educators alike. MOOC learners are usually interested in gaining an understanding of a subject topic or simply want to have an enjoyable experience through online learning, which may explain the high dropout rates. For educators, MOOCs open up opportunities for exploring new forms of pedagogy. The flipped classroom may be an answer to the question how MOOCs can be used to the full in the formal educational system.

The flipped classroom can tackle problems, such as inadequacy of autonomous learning with online materials, knowledge-based and teacher-centered instruction in the traditional classroom. The flipped classroom can take advantage of technology-enhanced learning materials offered on the Internet and support student-centered learning by face-to-face instruction in the classroom setting. In a word, effective application of the flipped classroom will be able to enhance the quality of formal education at different levels. The following section focuses on the discussion of the flipped classroom model for college English education in China.

\section{The Flipped Classroom Model for College English Education}

\section{Status Quo of College English Education}

A typical traditional English class in college looks like this: The teacher is the center of the class and imparts English language knowledge to the students, who passively listen to what the teacher says. Without much interaction between the teacher and the students or among the students, learning is limited to explicit knowledge, which is far from sufficient for language acquisition. From the cognitive perspective of second language acquisition, input, output, and interaction are all necessary for effective learning to take place (Ellis, 2005).

With students of different levels of language proficiency studying in the same classroom, it is very difficult for the teacher to deliver a lecture that benefits everybody. High achieving students often find the learning material too easy and cannot really gain much from the lecture, while low achievers may struggle with the same learning material and fail to follow the pace of teaching. Traditional teacher-centered instruction cannot meet the needs of individual students, thus limits their learning outcomes.

Due to previous exam-driven learning experience, many college students feel at sea when they need to 
decide what and how to learn by themselves. Research has also found that college students do not learn effectively in the virtual learning environment (GU, 2011). Many students are not yet used to the idea of autonomous learning, without teachers taking charge of their learning. Besides, they are not usually trained to use metacognitive learning strategies to plan, monitor, and evaluate their learning. Such skills, however, are essential for autonomous learning (Wenden, 1991).

Apart from learning on one's own, students in the 21 st century need to work with others in actual or virtual learning environments. In a traditional class, time is mainly devoted to the teaching of knowledge, so there is not enough time for collaborative activities, such as pair work, group discussion, or group projects. However, collaborative learning is believed to help the learner construct new understanding as he/she obtains different perspectives from other learners. The flipped classroom can free teachers and students from traditional class lectures and make time for problem solving and collaborative learning.

\section{The Flipped Classroom Based on Educational Objectives}

In college English classes, learners are expected to use English not only for daily communications, but also to fulfill academic purposes. They need to learn basic English skills, and they also need to understand and analyze information in English. Furthermore, they need to evaluate and criticize information using English. Ultimately, they are expected to write or create using English. The objectives of college English education can be interpreted by Bloom's taxonomy of educational objectives.

Bloom's taxonomy of educational objectives proposed in 1956 has been used in traditional education to design curriculum and class activities. In 2001, Anderson et al. revised Bloom's taxonomy in the cognitive domain. The new framework includes the following learning objectives, from simple to more complex types of cognitive process: remembering, understanding, applying, analyzing, evaluating, and creating (LI, 2016). The major differences between the original model and the revised one include renaming and re-positioning the components and explaining how the cognitive processes intersect different types of knowledge-factual, conceptual, procedural, and metacognitive. The different types of knowledge cannot be acquired through the traditional knowledge-transmitting approach.

In the traditional classroom, the low-order objectives like the first two levels of the learning objectives are more easily realized while the high-order objectives like evaluating and creating cannot always be addressed. In the flipped classroom, the high-order objectives can be taken seriously, with much more class time devoted to reflection, discussion, and creative work.

Built upon the framework of Anderson et al., the following Table 1 illustrates how the flipped classroom facilitates the fulfillment of the educational objectives.

The teaching approaches listed in the Table 1 are not brand new. They may well appear in discussions of pedagogy, but they were not previously labeled as flipped classroom approaches in the literature due to the absence of the flipped classroom concept. Now that the rationale of flipping the classroom becomes clearer in the Information Age, the teaching approaches need to be restructured to realize the potential objectives of the flipped classroom. 
Table 1

The Flipped Classroom Model

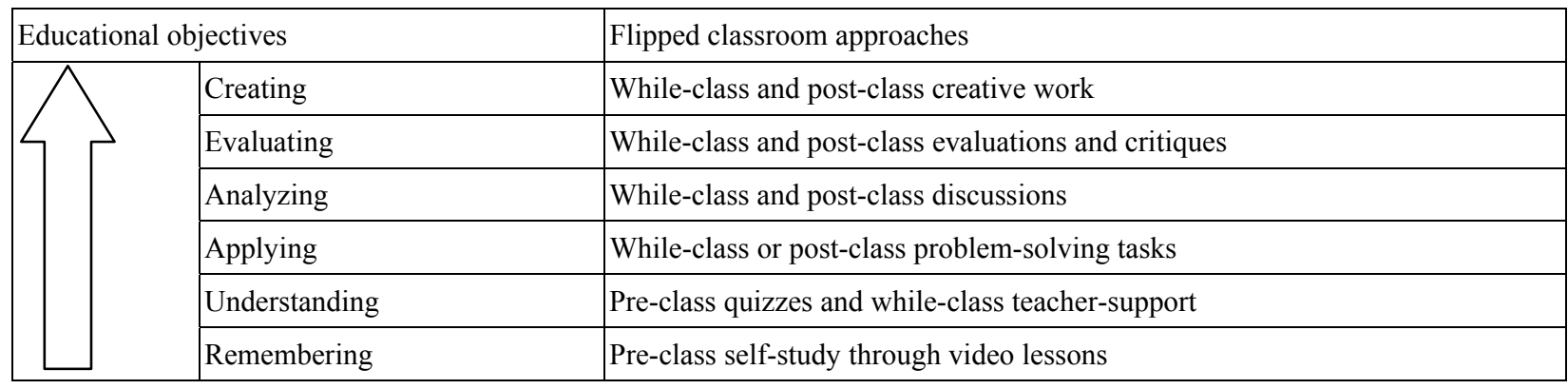

To make the flipped classroom approaches produce positive results in college English courses, teachers and students need to adjust their roles and work hand in hand to meet the opportunities and challenges.

Teachers. In flipped classrooms, the teacher's role is to guide students to think and discuss and to give professional advice and feedback (Hwang, LAI, \& WANG, 2015). Teachers are expected to participate throughout the learning process, from pre-class preparation to post-class tutoring.

Teachers need to make sure that students learn the target knowledge before class, so that meaningful discussions and collaborative learning can take place in class. Careful preparation should be made regarding what to present in the video lessons or what online resources to choose that are in line with course objectives. Along with video lessons, there are exercises that students need to complete before class. The web-based exercises provide instant feedback to teachers who can design classroom instruction to address problems students encounter.

Teachers play an important role in helping students achieve high-order educational objectives. Teachers guide and facilitate students' collaborative learning which involves high-order cognitive processing skills. To engage students in active learning that motivates them, teachers need to design creative learning tasks that get students to think critically and work collaboratively. Students may even be invited to participate in the task designing process.

The flipped classroom model will not work if students cannot learn independently. Teachers are expected to teach students to manage pre-class and post-class learning by employing metacognitive strategies, which are essential to self-regulated learning. Also, teachers have to get the course objectives across to the students who need to be responsible for their own learning outside the classroom and teachers should be ready to offer help whenever needed.

Students. The role of students in the flipped classroom model can be better fulfilled if students actively develop competence or skills in the following aspects.

First, language skills. The flipped classroom for college English courses makes language proficiency a major objective. Improving language proficiency is by no means an easy task. Students need to go through the three stages of skill acquisition proposed by Anderson (1980), namely, cognitive stage, associative stage, and autonomous stage. In the flipped classroom, much of the cognitive stage happens when students are involved in pre-class learning, acquiring factual and conceptual knowledge. Associative stage requires students to practice the language skills substantially in class and after class and autonomous stage follows when explicit knowledge turns into implicit knowledge. For college English learners, critical thinking and communicative ability of 
English are extremely important objectives. In the classroom, more time can be devoted to tasks where students take opportunities to work with the teacher and fellow students to achieve such objectives.

Second, learner autonomy. Instead of passively accepting what is taught by teachers, students in the flipped classroom model should take on a more active role in learning. Students have to learn on their own through pre-made videos or selected MOOCs, so as to get prepared for while-class tasks and activities. Apart from pre-class learning required by teachers, much of the learning conducted outside the classroom is self-initiated and self-regulated by students. It is imperative that students develop autonomous learning awareness and capability with the help of teachers.

Third, digital literacy. Digital literacy refers to the knowledge, skills, and behaviors in using digital devices, such as computers, tablets, or smartphones. The focus of digital literacy is on using these devices as networks, which builds upon traditional computer skills (https://en.wikipedia.org/wiki/Digital_literacy). Digital literacy can be very important to students in the flipped classroom, because pre-class learning materials are mostly presented in the form of digital information, and to enhance learning, students are also encouraged to find, use, evaluate, communicate, and create information using digital technologies, which include both digital hardware and software. As a result, special attention should be paid to students' digital literacy and specific training program should be organized to improve their digital literacy.

\section{Conclusion}

The study explores a model for applying the flipped classroom approaches to foreign language teaching in higher education. The implications of this study for research and practice of the flipped classroom include: (1) The flipped classroom model can be implemented in language courses that target all levels of the educational objectives; (2) information technology can be integrated into the flipped classroom model to enrich learning resources and facilitate learning; and (3) role adjustments of both teachers and students are essential to effective implementation of the flipped classroom. It is hoped that this paper will lead to more theoretical and empirical studies in the field and the new technology-enhanced instructional forms will produce real and lasting effects in pedagogical practices.

\section{References}

Anderson, J. R. (1980). Cognitive psychology and its implications. San Francisco: Freeman.

Digital literacy. (n.d.). In Wikipedia. Retrieved from https://en.wikipedia.org/wiki/Digital_literacy

Ellis, R. (2005). Principles of instructed language learning. System, 33, 209-224.

GU, S. M. (2011). On auxiliary college English teaching model in virtual learning environment- Quest for integrated framework of autonomous learning and cooperative learning. CAFLE, 6, 59-65.

Hwang, G. J., LAI, C. L., \& WANG, S. Y. (2015). Seamless flipped learning: A mobile technology-enhanced flipped classroom with effective learning strategies. Journal of Computers in Education, 4, 450.

Lage, M. J., Platt, G. J., \& Treglia, M. (2000). Inverting the classroom: A gateway to creating an inclusive learning environment. The Journal of Economic Education, 32(1), 32.

LI, Y. (2016). A study on teachers' teaching competence in the flipped classroom. Foreign Languages in China, 6, $19-26$.

Tucker, B. (2012). The flipped classroom. Education Next, 12(1), 82-83.

Wenden, A. L. (1991). Learner strategies for learner autonomy: Planning and implementing learner training for language learners. Hempel Hempstead and Englewood Cliffs, NJ: Prentice Hall.

YUAN, L., \& Powell, S. (2013). MOOCs and open education: Implications for higher education: A white paper. Retrieved from http://publications.cetis.ac.uk/2013/667 